\title{
NEPTUNE: \\ Real-Time Ocean and Earth Sciences at the Scale of a Tectonic Plate
}

\author{
Joln R. Delaney, G. Russ Heath, Bruce Howe \\ University of Washington $\bullet$ Seattle, Washington USA
}

Alan D. Chave

Woods Hole Ocanographic Institution - Woods Hole, Massadnusetts USA

Harold Kirklum

let Propulsion Laboratory - Pasadena, California USA

\section{Introduction}

Since the Challenger Expedition in the 1870s, oceanographers have explored and sampled across two-thirds of our planet using ships as primary observational platforms. In the past several decades, satelliteobserving systems have provided a much-needed synoptic overview of ocean surface characteristics. A growing number of instrumented moorings have been deployed in selected portions of the global ocean to obtain more continuous information about upper oceanic and atmospheric processes. Insights, knowledge, and models based on this exploratory phase of oceanography have resulted in growing recognition of the diversity and the complexity of processes that operate within and beneath the ocean basins. Indeed, we cannot answer many of the questions we can now pose using only the tools of the present. For this reason, the ocean sciences are on the threshold of a new era in which we must enter the entire ocean environment and establish interactive networks for in situ, adaptive observations of, and experiments with, key phenomena in the global earth-ocean system.

Many of these phenomena are dynamically intertwined with the complex processes that maintain habitability on earth. These processes include weather systems, ocean currents, climatic shifts, air-sea exchanges, primary-secondary productivity, deep ocean mixing, carbon sequestration, dynamics of fish populations, tectonic movements, earthquake patterns, volcanic eruptions, metal deposit formation, chemosynthetic habitats, and behavioral patterns of marine mammals.
Processes involved in each case exhibit episodic behavior tied to continually shifting forces operative within the planet's atmosphere, ocean, and crust. The complexity of earth-ocean-atmosphere interactions calls for a new research mode using recent advancements in computer sciences, robotics, and telecommunications, and in the power and sensor industries. These critical new technologies are allowing infrastructural changes that will progressively displace ships as the dominant observational platform for sustained time-series investigations in the oceans. An extensive and continual sensor/robotic presence must be established within the full ocean system to allow sustained observation and adaptive experimentation. Construction and servicing of such facilities is likely to require more ship time than we now utilize.

\section{Role of the National Oceanographic Partnership Program (NOPP)}

We began to develop new scientific ideas about how to specifically address some of these issues. We also recognized that, following the pioneering efforts of the LEO-15 program, we could embrace the very powerful concept of defining our system of interest as a plate and its overlying ocean. Technically, this idea required some very serious evaluation of the optimal approach to decadal, real-time, interactive observations and experiments on such a grand scale. We realized that for any investor-agency, foundation, or private sector-to take the concept seriously we had to have a document that 
demonstrated the feasibility of constructing a submarine network unlike anything in existence. We were encouraged to submit a proposal to NOPP for a paper study of the NEPTUNE concept, focusing on technical aspects. Our proposal received reasonably high marks in review, but was initially judged as too esoteric for consideration by the pragmatically oriented panel. Eventually funds were obtained to support the program on a $50 / 50$ basis with the four Phase 1 partners providing nearly \$ 0.5 million among them. The NEPTUNE Feasibility Study, which has received considerable attention, was released in June 2000 and is available at http://www.neptune.washington.edu. This study could not have been conducted without NOPP support.

\section{Figure 1}

A.

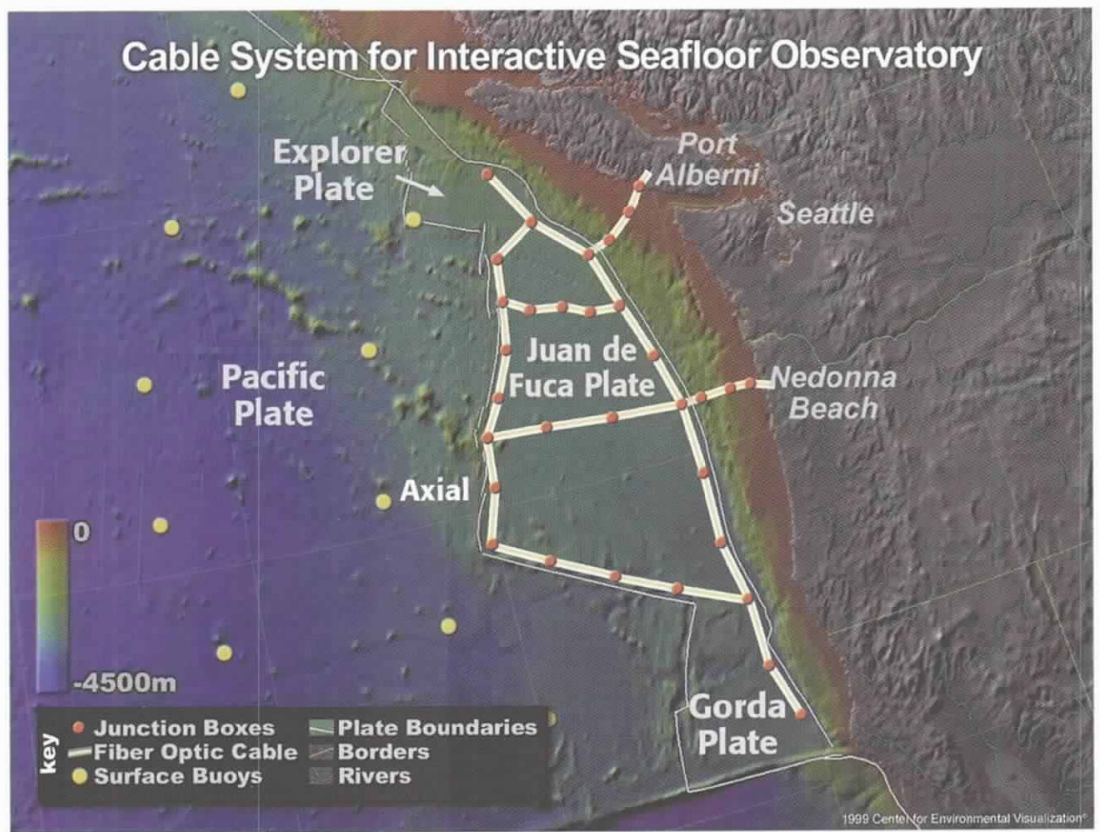

Just as importantly, however, the NOPP concept of matching support provided an endorsement from a nationally prominent group. Without NOPP it is unlikely that we could have persuaded our institutions to provide the risk capital for such a long shot.

\section{The Plate-Scale Observatory Concept}

The goal of the NEPTUNE project is to establish at tectonic plate scale, an undersea observatory based on fiber-optic/power networking that connects to the Internet many remote, interactive natural laboratory nodes designed for real-time, four-dimensional experiments on, above, and below the seafloor. Each of the natural phenomena listed above can be addressed in unique new ways using a NEPTUNE-like approach. The multidisciplinary NEPTUNE philosophy will optimize the investment required. Individual scientific communities would unlikely reach as broad a spectrum of potential users. NEPTUNE may appeal to ocean, earth, and atmospheric scientists, educators, policymakers, commercial fishing groups, and resource industries.

This NEPTUNE Plate-Scale Observatory is one element of the Dynamics of Earth and Ocean Systems (DEOS), a planning effort supported by the National Science Foundation's Ocean Sciences Division. The other two elements include: 1) a Global Ocean Network of approximately 20 seafloor seismic, magnetic, geodetic and oceanographic moorings,
B.

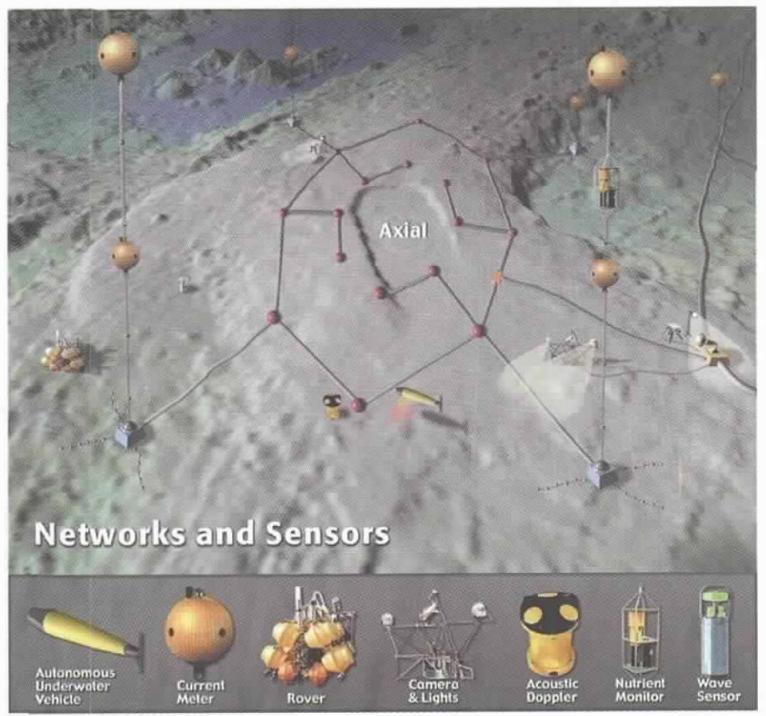

Figure 1: (A) The NEPTUNE network will provide considerable power to instrumented nodes and allow $\mathrm{Gb} / \mathrm{s}$ bandwidth for realtime data return and interactive control of sensor arrays and robotic vehicles. Moored buoys with full water-column instrument arrays will extend the reach of the system beyond the Juan de Fuca plate and its overlying ocean. The system will have a robust design, high reliability, the flexibility to grow, and will be sustained for a least 30 years. (B) NEPTUNE's experimental nodes, as depicted on Axial Seamount off the Oregon coast (and based on the NOAA/PMEL New Millenium Observatory), can facilitate detailed documentation and sampling before, during, and after major events. In the case of Axial, there have been several eruptions in the last decade. (Figures created by the Center for Environmental Visualization, University of Washington.)

${ }^{1}$ NEPTUNE Phase 1, Feasiblity Study (1998-2000), partners are the University of Washington, Woods Hole Oceangraphic Institution, Jet Propulsion Laboratory, and Pacific Marine Environmental Laboratory. 
and, 2) a suite of Relocatable Moored Buoy Observatories to be utilized anywhere in the world for 2-4 year comparative studies that will complement and extend the plate-scale studies.

NEPTUNE will be located in the northeastern Pacific (Figure 1) and spatially associated with the Juan de Fuca Plate. It will involve decadal studies of a broad suite of oceanographic and plate-tectonic processes. By combining fiber-optic/power networks and full water-column moorings, NEPTUNE's capabilities will allow the observation of processes that operate within the ocean and below the seafloor at scales up to 500 by $1000 \mathrm{~km}$. The network will provide significant power to instruments, high bandwidth for real-time data transmission, and two-way command-control capabilities for interaction with fixed instruments and with robotic undersea vehicles operated from shore. Remote, interactive experimental sites will be connected with land-based research

TABLE I

NEPTUNE ad hoc SCIENCE WORKING GROUPS

\title{
RIDGE-CREST PROCESSES
}

Chair: Meg Tivey, Woods Hole Oceanographic Institution

Participants: Suzanne Carbotte, Jim Cowen, Chris Fox, John Hildebrand, Debbie Kelley,

Anna-Louise Reysenbach, Ken Rubin, Tim Shank, Rick Thomson, Karen Von Damm

\author{
SEAFLOOR HYDROGEOLOGY AND BIOGEOCHEMISTRY: OPPORTUNITIES \\ FOR LONG-TERM BOREHOLE EXPERIMENTS \\ Chair: Earl Davis, Pacific Geoscience Centre \\ Participants: John Baross, Keir Becker, Bill Black, Andy Fisher, \\ Hans Jannasch. Richard Von Herzen, Spahr Webb \\ DEEP-SEA ECOLOGY \\ Chair: Ken Smith, Scripps Institution of Oceanography \\ Participants: Jim Barry, Stace Beaulieu, Lauren Mullineaux, Monty Priede, Bruce Robison, Tim Shank
}

\section{WATER-COLUMN PROCESSES}

Chair: D. B. Haidvogel, Institute of Marine and Coastal Sciences, Rutgers University

Participants: Mark Abbott, Jim Bellingham, Yi Chao, Ken Denman, Bruce Frost, Barbara Hickey, Zack Powell, Steve Riser, Rick Thomson

\section{SEISMOLOGY AND GEODYNAMICS}

Chair: William Wilcock, School of Oceanography, University of Washington

Participants: Donna Blackman, Ken Creager, Robert Detrick, Don Forsyth, Chris Fox, Roy Hyndman,

Steve Malone, Doug Toomey, Anne Tréhu, Kelin Wang, Spahr Webb, Doug Wiens

\section{SUBDUCTION ZONE PROCESSES: FLUID VENTING AND GAS HYDRATES AT THE CASCADIA CONVERGENT MARGIN}

Chair: Erwin Suess, GEOMAR

Participants: Robert Collier, Roy Hyndman, Keith Kvenvolden, Marvin Lilley, Ed de Long, Ko-ichi Nakamura, Charles Paull, Clare Reimers, Laurenz Thomsen, Michael Whiticar

CROSS-MARGIN PARTICULATE FLUX STUDIES ASSOCIATED WITH NEPTUNE

Chair: Charles A. Nittrouer, School of Oceanography, University of Washington

Participants: Wilford E. Gardner, Barbara M. Hickey, Paul S. Hill, Richard A. Jahnke, Richard G. Keil, Brent A. McKee, Andrea S. Ogston, Richard W. Sternberg, Peter A. Traykovski

\section{FISHERIES AND MARINE MAMMALS}

Chair: Waldo Wakefield, PMEL/NOAA

Participants: Ric Brodeur, Chris Fox, Bob Francis, Anne Hollowed, John Horne, Rick Methot, Julia Parrish, Bill Pearcy, Steve Ralston, Rick Thomson, Chris Wilson 
laboratories and classrooms. NEPTUNE may also serve as a unique testbed for sensor and robotic systems designed to explore other oceans in the solar system.

\section{Scientific Themes}

Scientific opportunities and needs will largely drive the NEPTUNE project, but the ultimate measure of success will be the quality of the scientific innovation and the educational benefits that the system enables. Because NEPTUNE can offer great opportunities to many areas of marine science, a broad spectrum of scientific studies is currently envisioned as part of the observatory network.

To explore the opportunities and needs of a broad range of marine scientists, ad hoc science working groups were convened during the past year (Table 1). Each group considered the research opportunities NEPTUNE could create and began to identify examples of

\section{Figure 2}

A.

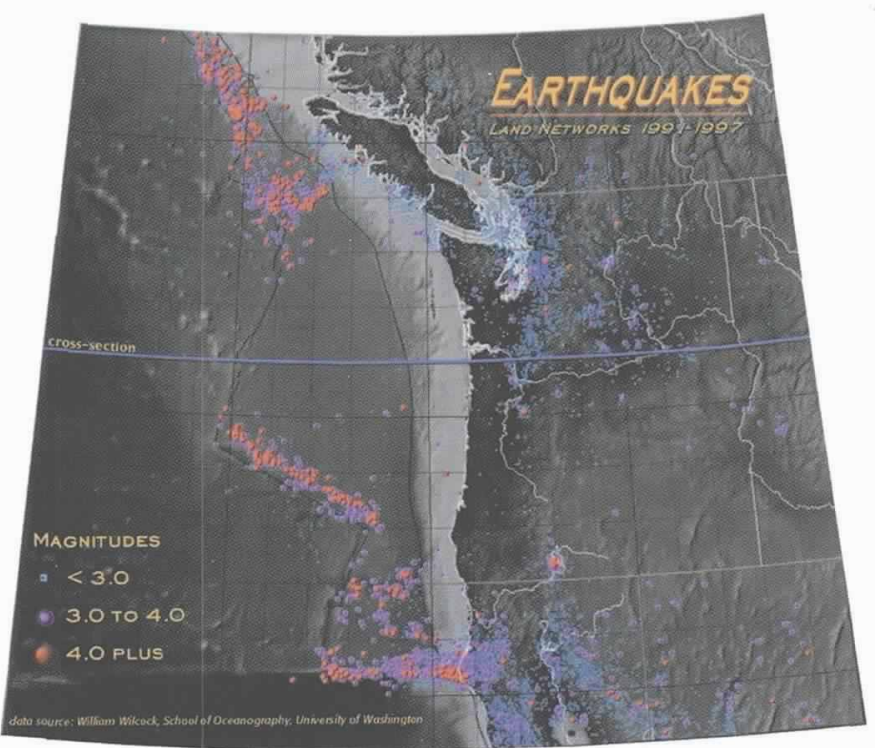

experiments and observations that could take advantage of certain capabilities. Most of the discussion focused on "community" experiments. These were defined as experiments required by two or more projects, those of long duration, i.e., beyond the length that a single principal investigator could be expected to support, those required by ongoing educational programs, or those in which many users would require the data. It was also recognized that NEPTUNE must serve individual principal investigators who would simply view it as a facility providing power and communications, allowing experiments to be conducted in exchange for standard charges based on connect time, bandwidth, and power in a manner analogous to use of a large telescope.

Out of these working groups came refined definitions of a series of capabilities that would be desirable to all groups. These scientific requirements are as follows:

- Bandwidth capable of supporting HDTV and acoustic tomographic studies at many nodes

- Power to operate autonomous underwater vehicles (AUVs) (see http://www.neptune.washington.edu/auv_white/pg1.html for a white paper on AUVs) and bottom rovers with a range of capabilities (some carrying rock drills, for example)

- Very accurate timing signals to support dense seismometer arrays

- Real-time information on the status of instruments

- Real-time ability to change measurement parameters and download data

- Reliable time series measurements, and user-friendly information management system. Several groups emphasized the importance of building in excess capacity so that the sophistication and scope of experiments can grow through time.

B.

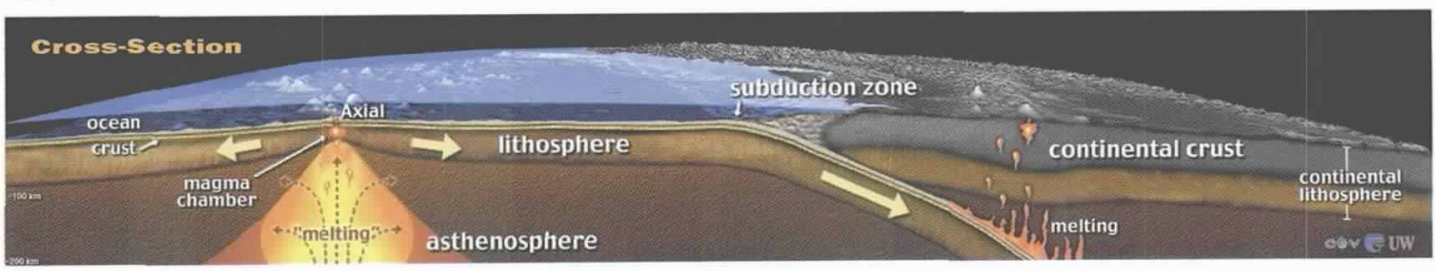

C.

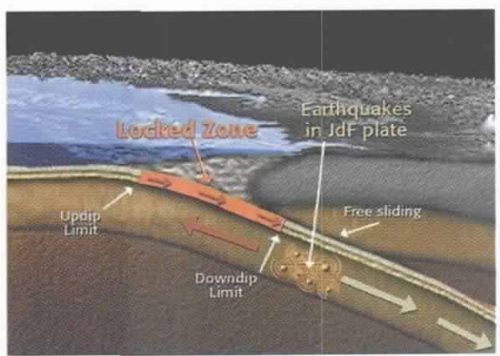

Figure 2: All major types of oceanic plate boundaries are found within the NEPTUNE study area. (A) This map shows earthquake activity from land-based seismic networks. These data establish that the Juan de Fuca plate is mostly seismically silent, implying it is behaving as a rigid plate analogous to many other larger plates. (B) Major geological components of the Juan de Fuca plate system are shown in this crosssection. (C) A cartoon showing that the upper and lower locked zones on the subducting plate are of critical interest to map out and examine through time. The last major earthquake in the Pacific Northwest was in January 1700, and there is considerable interest in detailed studies of how strain accumulates in both the on-land and at-sea portions of this type of system. (Figures created by the Center for Environmental Visualization, University of Washington, and posted in NEPTUNE Science White Paper \#2: Seismology $\mathcal{E}$ Geodynamics at http://www.neptune.washington.edu) 
Figure 3
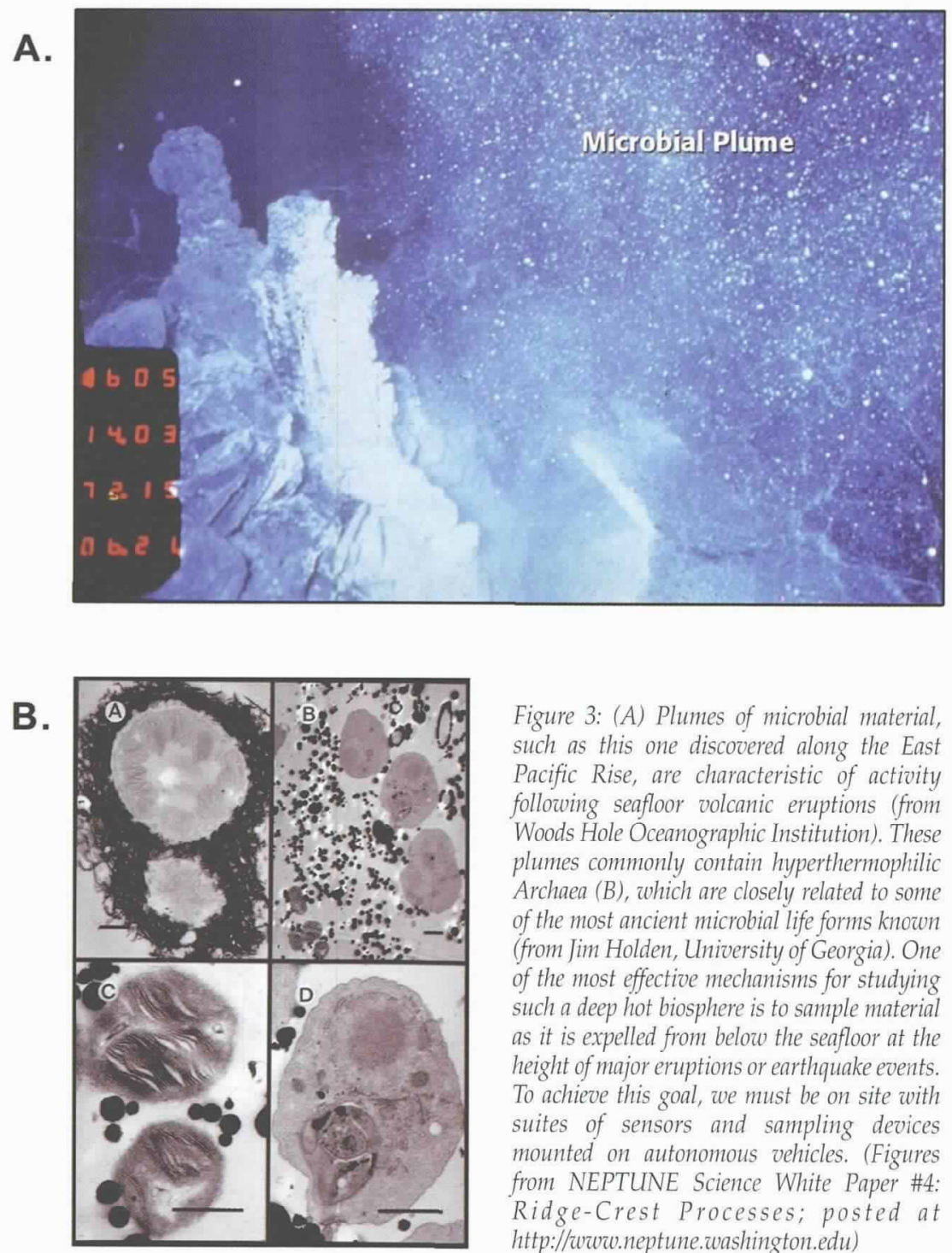

understanding of one such zone will provide guidance regarding similar Pacific Rim systems.

Ridge-crest processes: The specific nature of links and variations between geological, physical, chemical, and biological processes at active mid-ocean ridges is yet to be established. The next step in ridge-crest studies requires the capabilities supported by NEPTUNE: continuous, controllable experiments over periods of years and seafloorbased robotic vehicles that can be rapidly deployed (within hours) to monitor, observe, and record seismic or eruptive events (Figure 3 ). One of the main reasons for this approach is to ensure the capability to optimally sample the highest-temperature microbes that will be expelled from the deepest portions of an active volcano at the peak of the event. The discovery of a deep and hot volcanically supported microbial biosphere opens the potential for similar ecosystems on other planets (Delaney et al., 1998).

Seafloor hydrogeology and biogeochemistry: Instrumented boreholes within the oceanic crust can serve as laboratories for studying the interdependence of tectonics, fluid and thermal flows, and biological activity (Davis et al., 1995). NEPTUNE's provision of continuous power, high bandwidth, and realtime control will allow interactive experiments, such as hole-to-hole pumping, and long-term observations, not easily accomplished using traditional methods deployed from surface vessels (Davis and Becker, 1998).

Reports of the science working group meetings are available as white papers on the NEPTUNE web site at http://www.neptune.washington.edu. The following syntheses are provided to give a sense of the diversity of scientific inquiry that the NEPTUNE network could support.

Seismology and geodynamics: The NEPTUNE study area includes all major types of oceanic plate boundaries, including the Cascadia Subduction Zone (Fluck et al., 1997; Wang et al., 1997). There is global interest in understanding subduction earthquake behavior (Figure 2). The study site lies near the major population centers of Vancouver, Seattle, and Portland and has generated major earthquakes every few centuries (the last in January 1700). The plate-scale observations made possible by NEPTUNE will better define the nature, style, and causes of seismicity and deformation within this tectonic setting (Spiess et al., 1998; Fox and Dziak, 1999). A more thorough
Fluid venting and gas hydrates in subduction zone processes: Tectonically induced release of fluids and gases, such as methane, has been observed in zones of plate convergence around the globe (Bohrmann et al., 1998). Methane forms gas-hydrate deposits within the seafloor and is of major societal interest because of its suspected link to past episodes of climate warming, its role in chemosynthetically based benthic ecosystems, and its resource potential (Suess et al., 1999). The NEPTUNE study area includes a classic study site for fluid venting and for gashydrate formation and breakdown. (Figure 4)

Cross-margin particulate flux studies: Rugged terrain onshore, high coastal rainfall, and a narrow continental shelf combine to generate large fluxes of sediment across the northeast Pacific continental shelf to the adjacent deep-sea floor (Nittrouer and Wright, 1994). Yet the characteristics of the cross-margin flux, most of which occurs episodically during major storms, are poorly known. 


\section{Figure 4}
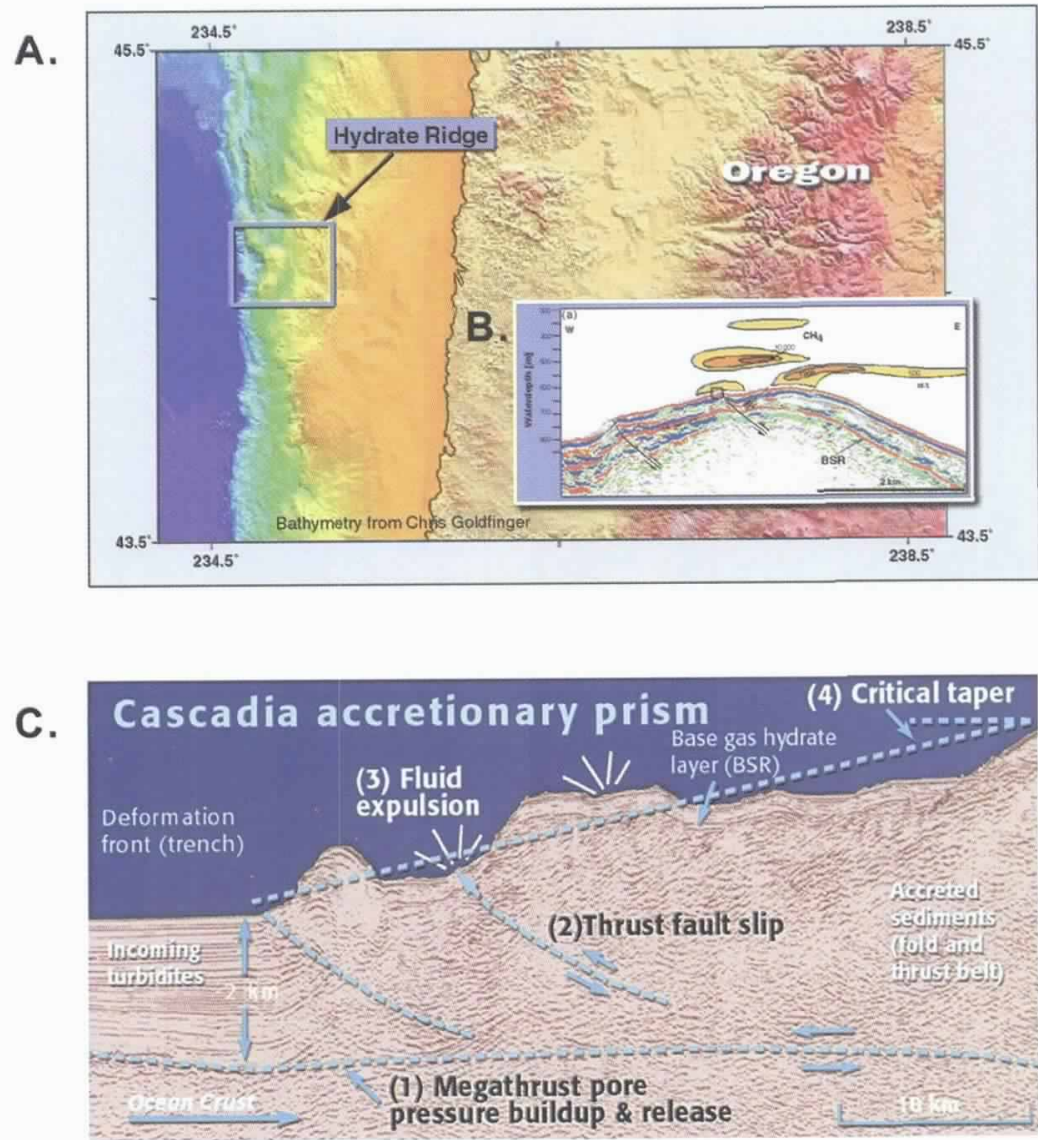

Figure 4: (A) Hydrate Ridge off the coast of Oregon where (B) methane plumes have been discovered in the ocean overlying hydrate deposits (from Suess et al., 1999). (C) Methane hydrate deposits are actively deforming in the accretionary prism and releasing unknown amounts of carbon into the overlying ocean and atmosphere (from R.D. Hyndman, Pacific Geoscience Centre, Geol. Suro., Canada). (D) A recent discovery was made of seafloor surface outcrops exposing methane hydrate (Suess et al., 1999), which can form (E) bedded deposits. (F) Chemosynthetically based benthic ecosystems, such as this vent fauna community are linked to hydrates. Interest in hydrate research is strong and societally relevant. NEPTUNE's capabilities will allow continuous assessment of and experimentation with the dynamics of these volatile resources. (Figures posted in NEPTUNE Science White Paper \#5: Subduction Zone Processes (Fluid Venting and Gas Hydrates) at http://www.neptune.washington.edu)
D.

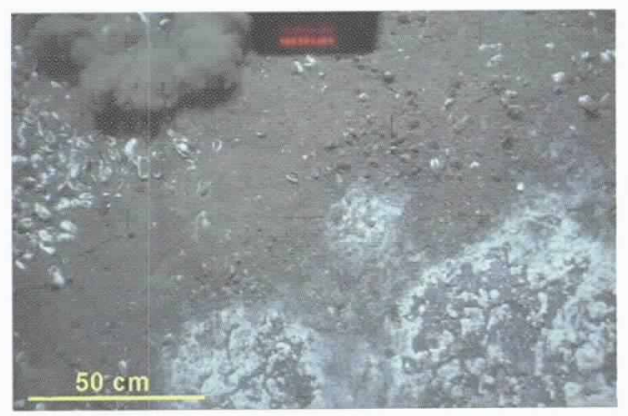

E.

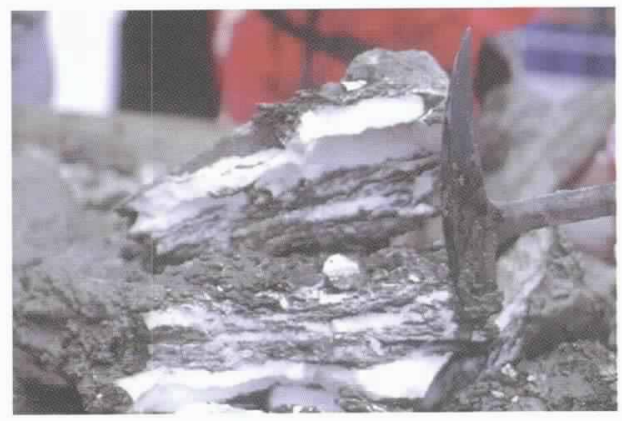

F.

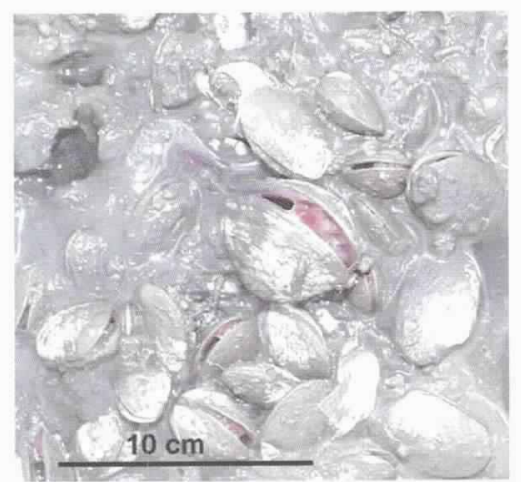

NEPTUNE's capabilities will permit measuring, sampling, and experimentation during such episodic events, and generalization to other similar environments.

Water-column processes: The NEPTUNE study area encompasses a region where many globally significant surface and bottom water processes occur, including deep surface mixing during winter storms and energy and mass transfer from the atmosphere to the ocean via coupled physical and biological processes (Figure 5). Collecting model-guided continuous, long-term data series will improve current physical-chemical-biological models of these processes and lead to a better understanding of their causes and consequences (e.g. Haidvogel et al., 2000; and Glenn et al., 2000).
Fisheries and marine mammals: Pioneering work in fisheries will be possible using the NEPTUNE network, particularly through applications of acoustic techniques (Priede and Bagley, in press). NEPTUNE's acoustic sensors will also allow detailed studies of the migratory patterns and feeding behavior of whales, including blue whales, and other large marine mammals (McDonald and Fox, 1999; Moore et al., 1998).

Deep-sea ecology: Despite the fact that it represents about 60 percent of the planetary surface, only a small percentage of the biota of the deep sea has been sampled or identified. Even less has been observed in sufficient detail to begin to unravel ecosystem structure and functions (Smith et al., 1997). By allowing extensive spa- 
tial and temporal sampling, measurements, and in situ experiments, the NEPTUNE network will develop a functional understanding of the ecology of deep-sea communities (Smith and Kaufmann, 1999).

\section{Cross-Cutting Themes}

The ability to make synchronous measurements covering an entire lithospheric plate and its overlying water column for decades will allow exploration and testing of a broad suite of hypotheses involving expected (and unexpected) linkages and feedback mechanisms. Examples include connections among tectonic, volcanic, hydrothermal, and biological phenomena along ridge crests. Simultaneity of activity among events on ridge crests, ridge flanks, fracture zones, and segments of the subduction zone has rarely been hypothesized but may well happen. Interactions involving plate boundary processes and the distribution of strain within the plate itself could be a powerful predictor of major earthquakes. Triggering events involving seismicity, mass sediment movements, gas release and chemosynthetic biological communities along the convergent margins are not now recorded, but should occur.

Interplay among ocean circulation, primary productivity, pelagic and benthic food webs, including fisheries, and the carbon cycle from a coastal upwelling regime to the open sea can be explored in four dimensions. Relationships linking sea-surface phenomena observable by satellite sensors and processes operating within contiguous subjacent volumes of ocean will enhance the effectiveness and generalizable value of both techniques.

Because NEPTUNE will allow synchronous measurements across time scales of seconds to decades (a range of $10^{9}$ ) it will be possible for the first time to cross correlate water-column and seafloor processes. Indeed, by using the time domain as an additional axis along which to simultaneously examine a broad range of processes, we are likely to discover hitherto unexpected cause and effect relationships. As the NEPTUNE archive grows, the potential for mining the databases in search of connections that are unanticipated will also grow and its utility in educational pursuits may become profound.

\section{Education}

Education was another cross-cutting theme that emerged from all of the working group meetings and will be a vital component of the NEPTUNE program. The infrastructural requirements for educational programs are more than met by fulfilling the scientific requirements. With its Internet capabilities, NEPTUNE will provide real-time output from some of the most dynamic of earth-ocean systems. NEPTUNE products will offer rich educational opportunities for students of all ages and will be well-suited for use in classrooms, laboratories, and even the living rooms of interested learners. National-level NEPTUNE-sponsored work- shops will generate strategies for developing K-12 curricula, establishing an undergraduate research programs, and designing exhibits for public museums and aquariums. At least one experimental node will be devoted to use by classes of potential oceanographers.

\section{Figure 5}

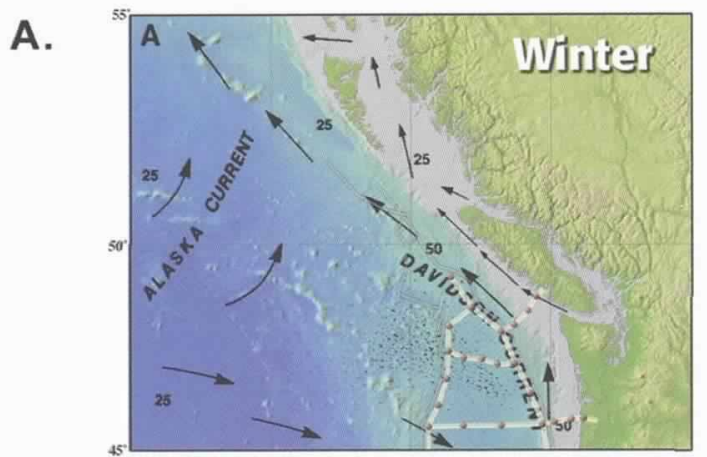

B.

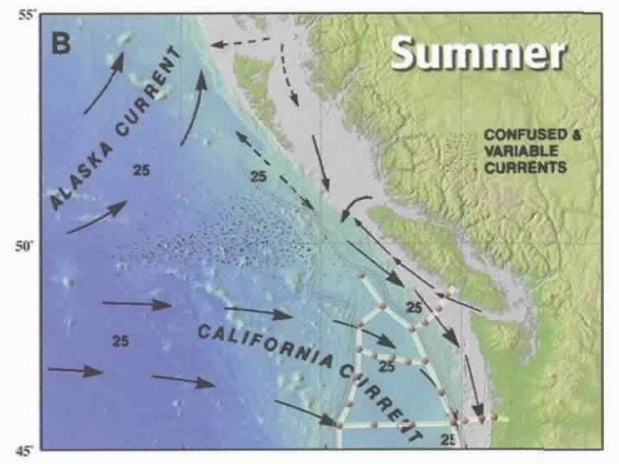

C.

\section{Coast Watch NOAA-14 Satellite Pass 1999/12/27 14:38:09 PST}

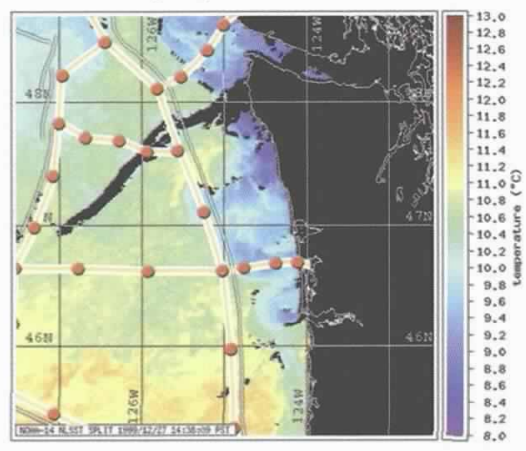

Figure 5: (A and B) This map of prevailing surface circulation off the British Columbia-Washington coast in winter and summer indicates the variability of ocean circulation patterns. Broken arrowes indicate uncertain currents. Numbers give speed in $\mathrm{cm} / \mathrm{s}$. (Figures adapted from Thomson, 1981.) (C) This image of NOAA sea-surface temperatures off the West Coast is derived from satellite data. NEPTUNE's measurements will enhance the value of satellite-based remote sensing by continuous "sea-truth" throughout the volume of ocean imaged. This time-series characterization can be at a resolution and synopticity that has heretofore been unobtainable. (Figures adapted by the Center for Environmental Visualization, University of Washington, and posted in NEPTUNE Science White Paper \#7: WaterColumn Processes at http://wwwoneptune.washington.edu) 


\section{Observatory Infrastructure}

NEPTUNE is an integrated system designed to provide power and communication, in real time, to a fiber-optic network linking heavily instrumented nodes distributed throughout an active seafloor area and its overlying ocean covering an area of at least 500 by 1000 $\mathrm{km}$. The NOPP-supported NEPTUNE Feasibility Study demonstrated that a cabled system can deliver considerable power and communications bandwidth with reliability and flexibility at an affordable price.

The NEPTUNE system must have the following characteristics to meet the scientific requirements:

- Plate scale (covering the full Juan de Fuca tectonic plate)

- Power (order of tens of $\mathrm{kW}$ )

- Bandwidth (order of many Gb/s)

- Real-time data return and robotic control capability

- Robust design for high reliability

- Precision timing at all instruments

- Available for nominally 20 - 30 years

The major power consumers will include those instruments that require motion (AUVs, pumps), heat transfer (freezers to preserve specimens, heaters for polymerase chain reactions used in DNA work, heaters for clathrate studies), light (video), and "hotel" electronics. The basic needs can be met with $2-10 \mathrm{~kW}$ per node. Designs indicate that much as $100 \mathrm{~kW}$ overall can be delivered for the entire 30-node scenario. The major consumers of communications bandzidth are video and high-frequency acoustics; significant fractions of a gigabit per second are required at a node, with order 10 $\mathrm{Gb} / \mathrm{s}$ required overall.

We have selected a mesh network topology for the power and communications systems to meet the capacity requirements of both and to maximize reliability and flexibility. For power, this means using a "parallel" or constant voltage approach much like land power grids and unlike conventional submarine telecommunications systems. While DC is the obvious choice for power delivery, very low frequency $\mathrm{AC}$ (less than 1 $\mathrm{kHz}$ ) is being considered, as a means to extend the life of the cable insulation (Rabinowitz, 2000). For communications, we are recommending gigabit Ethernet, the high-speed version of a widely used data networking technology (Kadambi et al., 1998). NEPTUNE will appear as a seamless extension of the global Internet, connecting users anywhere on shore to the sensors on the seafloor.

Sensor neturorks attached to NEPTUNE should be ever-evolving; the design and working architecture must support this requirement. We expect that tethered remotely operated undersea vehicles of many types will be essential for installing and maintaining the systems. More importantly, AUVs and bottom rovers will be highly mobile platforms for the scientific use.
The NEPTUNE data management and ardioing system will allow scientists and other users efficient and seamless access to NEPTUNE data. An approach is planned based on distributed archiving of selected data, combined with robust and reliable data access and mining tools.

\section{Environmental and Legal Considerations}

Because some portions of the NEPTUNE cable will be laid on public submerged lands, the program will be subject to several legal and regulatory requirements of state and federal agencies. Other entities with vested interests in NEPTUNE are the U.S. Navy, Native American tribes, fishing organizations, environmental groups, coastal communities near NEPTUNE shore landings, and telecommunication companies. We recognize the importance of developing and maintaining good communication with all stakeholder groups, and we have already held several meetings involving such groups, with favorable results.

\section{Project Coordination and Management}

A NEPTUNE Office at the University of Washington will work closely with its institutional partners to coordinate the activities of partners, integrate scientific planning, support technical system design, anticipate permitting and environmental requirements, handle much of the fund raising, and act as liaison with agency, industry, and international collaborators. Our Canadian colleagues held an inaugural NEPTUNE meeting on March 3 and 4, 2000, which was attended by 65 Canadians, including one Cabinet Minister.

\section{Costs and Timeline}

Estimated costs for NEPTUNE, in year 2000 dollars, are $\$ 100$ million for plate-scale infrastructure, $\$ 100$ million for community science experiments, and $\$ 10$ million/year in operating costs. NEPTUNE operations will begin in 2004; the system will have a 30-year lifetime. See the NOPP-supported NEPTUNE Feasibility Study at http://www.neptune.washington.edu for details.

\section{Final Comment}

The NEPTUNE program offers exciting opportunities to move ahead in three broad areas. First, the system as envisioned will enable deployment of an observing network of unprecedented density, variety, and spatial coverage, including novel instrumentation for sensing the combined in situ physical-chemical-biological environment on, below, and above the seafloor. Second, assimilative models can be applied to design an adaptive NEPTUNE observational system. This approach would take advantage of the ability to sample 
completely, at selected scales, blocks of ocean in four dimensions. With experience it may be possible to forecast episodic oceanic events, and adaptively redirect the deployment of movable observational platforms in either anticipation or response. Third, the availability of a unified observing/modeling system for the NEPTUNE region will allow scientists to address issues of process-coupling across multiple spatial and temporal scales. Properly configured and executed, NEPTUNE may become the equivalent of a ship that sails through time, not space. In this sense it represents an additional step toward conducting oceanographic research and education in the 21st century.

\section{REFERENCES}

Bohrmann, G., J. Greinert, E. Suess and M. Torres, 1998: Authigenic carbonates from the Cascadia subduction zone and their relation to gas hydrate stability. Geology, 26, 647-650.

Davis, E.E., K. Becker, K. Wang and B. Carson, 1995: Long-term observations of pressure and temperature in Hole 892B, Cascadia Accretionary Prism. In: Proc. ODP, Sci. Results, 146 (Pt. 1). B. Carson, G.K. Westbrook, R.J. Musgrave and E. Suess, eds., Ocean Drilling Program, College Station, TX, 299-311.

Davis, E.E. and K. Becker, 1998: Borehole observatories record driving forces for hydrothermal circulation in young oceanic crust. EOS, 79, 369-378.

Delaney, J.R., D.S. Kelley, M.D. Lilley, D.A. Butterfield, J.A. Baross, W.S.D. Wilcock, R.W. Embley and M. Summit, 1998: The quantum event of oceanic crustal accretion: Impacts of diking at mid-ocean ridges. Science, 281, 222-230.

Fluck, P., R.D. Hyndman and K. Wang, 1997: Threedimensional dislocation model for great earthquakes of the Cascadia subduction zone. J. Geoplyys. Res., 102, 20,539-20,550.

Fox, C. G. and R. P. Dziak, 1999: Internal deformation of the Gorda Plate observed by hydroacoustic monitoring. J. Geophys. Res., 104, 17, 603 - 17,616.

Glenn, S. M., T.D. Dickey, B. Parker and W. Boicourt, 2000: Long-term real-time coastal ocean observation networks. Oceanography, 13, 24-34.

Haidvogel, D.B., J. Blanton, J.C. Kindle and D.R. Lynch, 2000: Coastal ocean modeling: Processes and realtime systems. Oceanographly, 13, 35-46.
Kadambi, J., I. Crayford and M. Kalkunte, 1998: Gigabit Ethernet. Prentice Hall, New Jersey, 365 pp.

McDonald, M.A. and C.G. Fox, 1999: Passive acoustic methods applied to fin whale population density estimation. J. Acoust. Soc. Anl., 105, 2643-2651.

Moore, S.E., K.M. Stafford, M.E. Dahlheim, C.G. Fox, H.W. Braham, J.J. Polovina and D.E. Bain, 1998: Seasonal variation in reception of fin whale calls at five geographic areas in the North Pacific. Marine Mammal Sci., 14, 617-627.

Nittrouer, C.A. and L.D. Wright, 1994: Transport of particles across continental shelves. Ret. Geophys., 32, 85113.

Priede, I.G. and P.M. Bagley, 2000: In situ studies on deep-sea demersal fishes using autonomous unmanned lander platforms. Ocennogr. Mar. Biol. Annu. Rec., in press.

Rabinowitz, M., 2000: Power Systems of the Future, Part 2. IEEE Power Engineering Rez., 20, 10-29.

Smith, K.L., Jr., R.C. Glatts, R.J. Baldwin, S.E. Beaulieu, A.H. Uhlman, R.C. Horn and C.E. Reimers, 1997: An autonomous, bottom-transecting vehicle for making long time-series measurements of sediment community oxygen consumption to abyssal depths. Limnol. Oceanogr., 42, 1601-1612.

Smith, K.L., Jr., and R.S. Kaufmann, 1999: Long-term discrepancy between food supply and demand in the deep Eastern North Pacific. Science, 284, 1174-1177.

Spiess, F., D. Chadwell, J. Hildebrand, L. Young, G. Purcell and H. Dragert, 1998: Precise GPS/acoustic positioning of sea floor reference points for tectonic studies. Phys. Earth Planet. Inter., 108, 101-112.

Suess E., M. Torres, G. Bohrmann, R. Collier, J. Greinert, P. Linke, G. Rehder, A. Trehu, K. Wallmann, G.Winckler and E. Zuleger, 1999: Gas hydrate destabilization: Enhanced dewatering, benthic material turnover and large methane plumes at the Cascadia convergent margin. Earth Plan. Sci. Lett., 170, 1-15.

Thomson, R.E., 1981: Oceanography of the British Columbia Coast. Canadian Special Publication of Fisheries and Aquatics Sciences 56, Ottawa, 291 pp.

Wang, K., J. He and E. E. Davis, 1997: Transform push, oblique subduction resistance, and intraplate stress of the Juan de Fuca plate. J. Geophys. Res., 102, 661674.

Qd 